\section{Kidney \\ Blood Pressure Research}

Kidney Blood Press Res 2016;41:29-39

DOI: $10.1159 / 000368544$

Published online: January 08, 2016

Accepted: November 17, 2015

This is an Open Access article licensed under the terms of the Creative Commons AttributionNonCommercial 3.0 Unported license (CC BY-NC) (www.karger.com/OA-license), applicable to the online version of the article only. Distribution permitted for non-commercial purposes only.

\title{
Hypertensive/Microvascular Disease and COPD: a Case Control Study
}

\author{
Sky KH Chew ${ }^{\mathrm{a}}$ Deb Colville ${ }^{\mathrm{a}}$ Piers Canty $^{\mathrm{a}}$ Anastasia Hutchinson ${ }^{\mathrm{a}} \quad$ Alex Wong $^{\mathrm{a}}$ \\ Vi Luong $^{\mathrm{a}}$ Tien Y Wong ${ }^{\mathrm{b}}$ Christine McDonald $^{\mathrm{c}}$ Judy Savige ${ }^{\mathrm{a}}$ \\ aThe University of Melbourne Department of Medicine (Northern Health), Epping, Australia; 'bSingapore \\ Eye Research Institute, Yong Loo Lin School of Medicine, National University of Singapore, Singapore; \\ 'Department of Respiratory and Sleep Medicine, Austin Health, Heidelberg, Australia
}

\section{Key Words}

Microvascular retinopathy $\cdot$ Hypertension $\cdot$ Chronic obstructive pulmonary disease $•$ Cardiac risk

\begin{abstract}
Background/Aims: This study tested the hypothesis that individuals with chronic obstructive pulmonary disease (COPD) have more small vessel disease and more severe disease than an age- and gender- matched hospital patient comparison group. Methods: This was a single centre, case-control study of 151 individuals with COPD (FEV1/VC) < 0.7 recruited consecutively immediately after respiratory function tests at a Melbourne teaching hospital over a 4 month period in 2010. Controls were individuals with normal respiratory function tests recruited contemporaneously from the same centre. Retinal images were obtained with a nonmydriatic camera (KOWA or Canon CR5-45NM), deidentiifed and graded by two trained graders for microvascular retinopathy (Wong and Mitchell classification), and vessel calibre using a computer-assisted method and Knudtson's modification of the Parr-Hubbard formula. Differences in microvascular retinopathy and vessel calibre between COPD patients and the comparison group were examined using Fisher's exact test or the t test (StataCorp, Texas). Results: Patients with COPD had more microvascular retinopathy $(121,80 \%$ and $76,50 \%$; OR 3.98, 95\%CI 2.39 to 6.64 ) and more severe disease (42, $28 \%$ and $18,12 \%$; OR 2.85, 95\% CI 1.55 to 5.23) than other hospital patients. COPD remained an independent determinant of microvascular retinopathy (OR 4.56, 95\%CI 2.49 to 8.36) after adjusting for gender, hypertension, smoking, and diabetes duration. Retinal arterioles and venules were wider in patients with COPD than other hospital patients (mean difference $+6.5 \mu \mathrm{m}, 95 \%$ confidence interval 1.4 to 11.6 ; and $+17.4 \mu \mathrm{m}, 95 \%$ CI 9.4 to 25.5 , respectively). Larger venules were more common in younger individuals $(+0.6 \mu \mathrm{m}, 0.1$ to 1.17$)$ with more cigarette exposure $(+0.3$ $\mu \mathrm{m}, 0.2$ to 0.5$)$ or a lower serum albumin $(+23.0 \mu \mathrm{m}, 6.0$ to 40.0$)$. Venular calibre was not different in current and former smokers $(p=0.77)$. There were trends for venules to be larger with more severe COPD (lower FEV1/VC, $\mathrm{p}=0.09$ ) and with $\mathrm{CT}$-demonstrated emphysema




\section{Kidney \\ Blood Pressure Research}

$(p=0.06)$. Conclusions: Hypertensive/microvascular disease is more common and more severe in patients with COPD. This is likely to contribute to the associated increase in cardiac risk.

Copyright $@ 2016$ S. Karger AG, Basel

\section{Introduction}

Chronic obstructive pulmonary disease (COPD) affects 10\% of adults over the age of 40 , and is a leading cause of ill-health and death [1]. It is characterised by airflow limitation due to inflammation and remodelling, but is more complex than airways disease alone. Thus, extrapulmonary complications are common, including vascular disease, diabetes, malnutrition, osteoporosis, depression, and macular degeneration [2-5].

Patients with COPD are more likely to be diagnosed with cardiovascular disease (OR 2.46 95\% CI 2.02-3.00; $<<0 \cdot 0001$ ), with a two to five times greater risk of ischaemic heart disease, cardiac arrhythmias, heart failure, or arterial disease [6]. In addition patients with COPD are more likely to have hypertension (OR 1.33, 95\% CI 1.13-1.56; $p=0 \cdot 0007$ ).

Most patients with COPD have been smokers and smoking contributes to many of these complications. Smoking affects the vasculature, blood pressure, and renal function, through diverse mechanisms such as oxidative stress, endothelial dysfunction, hypoxaemia and autonomic dysregulation [7-9]. However, smoking-independent mechanisms may also be important, and the release of inflammatory mediators from the lungs into the systemic circulation is increasingly recognised in the initiation and exacerbation of comorbid disease [2].

Most previous studies of cardiac disease in COPD have focused on coronary artery stenosis, and ignored small vessel disease. No previous study has examined small vessel disease in COPD, apart from one that found an association between larger venular calibre and a reduction in FEV1, FEV1/VC and lung density ( $\mathrm{p}$ all < 0.05) [10].

Hypertensive/microvascular retinopathy is associated with an increased risk of cardiac events $[11,12]$. Characteristic features include diffuse and focal arteriolar narrowing, arteriovenous nicking, haemorrhage and exudates. Arteriolar narrowing and venular dilatation are both also associated with increased cardiac risk. However the determinants of small vessel calibre are complex. For example, arteriole calibre is reduced in males and with increasing age, hypertension, atherosclerosis and renal failure [13]. Venular calibre is increased in diabetes, smoking, inflammation, obesity, dyslipidemia and hypoxemia $[11,14-$ 17].

The present study determined the frequency and severity of hypertensive/microvascular retinopathy features including calibre, in a single centre cohort of individuals with COPD. Retinal small vessel examination represents a surrogate for direct examination of the systemic microvasculature.

\section{Materials and Methods}

\section{Study design}

This was a single centre, case-control study of Caucasian individuals with COPD recruited consecutively from a Melbourne metropolitan teaching hospital (Northern Health) over a 4 month period in 2010. The comparison group were age- and gender-matched hospital patients with normal respiratory function tests recruited during the same period. The researchers were undergraduate medical students who were seconded to a research project.

Recruitment, data capture and retinal photographs were coordinated in a single episode. Participants with COPD or with normal respiratory function tests were recruited immediately after testing. They were then assisted by the researcher to complete a basic structured demographic and medical questionnaire and to undergo retinal photography. Participants were not assessed for behavioural information apart from 


\section{Kidney \\ Blood Pressure Research}

Kidney Blood Press Res 2016;41:29-39

\begin{tabular}{l|l}
\hline DOI: $10.1159 / 000368544$ & (C) 2016 S. Karger AG, Basel
\end{tabular}

Published online: January 08, 2016

www.karger.com/kbr

Chew et al.: Hypertensive/Microvascular Disease and COPD

smoking history, and cigarette pack years. Retinal images were examined for microvascular retinopathy and vessel calibre at the Centre for Eye Research Australia. The frequency and severity of retinal abnormalities were then compared between COPD patients and the comparison group, and the likely determinants examined in a multivariate analysis. There were no changes to the study design after its commencement and no interim analyses.

The study was approved by the Northern Health Human Research Ethics Committee according to the Principles of the Declaration of Helsinki, and all participants provided signed, informed consent.

Participants

Participants with COPD or with normal respiratory function tests were recruited immediately after testing.Respiratory tests were performed using a computerized spirometer (Sensor Medics Legacy 29D, Yorba Linda, USA) by a trained technician according to a standard protocol $[18,19]$.

COPD was diagnosed when participants had a ratio of forced expiratory volume in one second (FEV1) to forced vital capacity (FVC) $<70 \%$ and no increase after bronchodilator treatment [20]. Individuals were recruited regardless of whether they were newly-diagnosed or treated, and whether they had diagnosed hypertension or not. There was no randomisation of participants.

The controls were age- and gender-matched hospital clinic patients with normal respiratory function tests, and no previous diagnosis of COPD, asthma or bronchiectasis. They were approached as they waited for respiratory function testing or for medical clinic review.

Hypothesis

Our hypothesis was that small vessel disease was more abundant and more severe in subjects with COPD than in an age- and gender-matched comparison group.

\section{Outcomes}

The primary outcome was to demonstrate an association of COPD with microvascular retinopathy or changed retinal vessel calibre. The secondary outcome was to demonstrate that any effect was independent of other vascular risk factors.

\section{Eligibility criteria}

Inclusion criteria were age over 18 years, FEV1/VC $<70 \%$ without an increase after bronchodilator therapy, and the provision of written informed consent. Exclusion criteria were where the vessel calibre in the retinal images was ungradeable.

\section{Measurements}

Clinical features: Participants were assisted to complete a structured questionnaire for demographics (age, gender, race), and vascular risk factors (smoking, cigarette pack years, diabetes, hypertension, dyslipidemia), and laboratory test results (haemoglobin, lipids, estimated glomerular filtration rate [GFR] based on the MDRD formula) were obtained from their electronic medical records. Generally, the diagnoses of hypertension, diabetes and dyslipidemia were based on self-reported physician-made diagnoses (resting $\mathrm{BP} \geq 140 / 90 \mathrm{~mm} \mathrm{Hg}$; random blood sugar $\geq 11.1 \mathrm{mmol} / \mathrm{L}$; the need for statin treatment, respectively). A list of current medications was extracted from the medical record, and the number of antihypertensive agents counted for each participant by a physician. The extent of cigarette use was recorded as cigarette pack years. A low serum albumin was defined as $<36 \mathrm{~g} / \mathrm{l}$. Emphysema was demonstrated radiologically on a chest computerized tomographic (CT) scan within the previous 12 months.

COPD: COPD severity was graded according to the 'GOLD' Guidelines (Global Initiative for Chronic Obstructive Lung Disease, www.goldCOPD.org). Briefly, mild COPD severity corresponded to FEV1 > 80\% normal; moderate to FEV1 50 - 79\% normal; severe to 30 - 49\% normal; and very severe to FEV1 <30\% normal. The use of home oxygen therapy but no other COPD-specific treatment was noted.

Retinal imaging and grading for retinopathy: All participants underwent colour retinal photography of both eyes using a non-mydriatic retinal camera (KOWA 7, Optimed, or Canon CR5-45NM, Canon, Japan). Standard $45^{\circ}$ images were taken of both eyes, with at least one centred on the macula and another on the optic disc. All retinal images were deidentified, examined for incidental abnormalities and haemorrhage 


\section{Kidney \\ Blood Pressure Research}

with red-free manipulation, and graded for microvascular retinopathy (Wong and Mitchell classification) [21], independently by two trained graders, an ophthalmologist and a medical student. In all cases, the grade of the more severely-affected eye was used. Any disparities in grading were discussed, and a consensus reached.

Microvascular retinopathy was classified as mild (arteriovenous nicking, focal arteriolar narrowing, silver-wiring or a decreased arteriovenous ratio), moderate (haemorrhage or exudates) or severe (papilloedema).

Retinal calibre measurements: Retinal vessel calibre was measured by a trained grader at the Centre for Eye Research Australia (Victoria, Australia) who was masked to subject identity and used a standardized protocol $[22,23]$. All vessels passing through a zone 0.5-1 disc diameters from the optic disc margin were examined using a semi-automated computer imaging program (University of Wisconsin, WI), and measures based on the 6 largest vessels were combined into the Central Retinal Artery and Vein Equivalents (CRAE and CRVE). This method was highly reproducible with intra-class correlation coefficients of 0.99 (95\% CI $0.98-0.99)$ for the CRAE and 0.94 (95\% CI 0.92- 0.96) for the CRVE.

\section{Sample size}

This represented a pilot study since there were no previous data that enabled us to determine an appropriate participant number.

\section{Statistical methods}

Differences in clinical characteristics and vessel calibre between patients with COPD and the comparison group were compared using Fisher's exact test or the $t$ test.

Possible determinants of retinopathy or calibre were examined using univariate linear regression. Likely determinants of retinopathy and calibre were then examined in multivariate regression models. Statistical analyses were performed using GraphPad or STATA version 11.2 software (Stata Corp, College Station, TX, USA). Statistical significance was set at $\mathrm{p}<0.05$ and trends at $<0.10$.

\section{Results}

\section{Clinical features}

One hundred and fifty-four patients with COPD and 156 of the comparison group were recruited. The recruitment rate was $>95 \%$ of the individuals approached in each group. Three patients with COPD and 5 controls were excluded because their retinal images were ungradeable. These were the only exclusions. This meant that the results from 151 cases and 151 of the comparison group were studied.

Patients with COPD had an average age of $69 \pm 9.7$ years (range $42-78$ years) and $80(53 \%)$ were male (Table 1). Their mean FEV1:VC was 50\% (range 21-69), and their mean $\mathrm{FEV}_{1}$ was $53 \%$ (range 17-107). Most (143,95\%) had been smokers with an average cigarette exposure of $46.2 \pm 27.3$ pack years. Eight had never smoked but had long-term exposure to smoke and/ or occupational dusts.

Overall, patients with COPD were more likely to have been smokers, to have smoked more, to require more anti-hypertensive medications, and to have worse renal function than other hospital patients (Table 1). However, COPD patients were not different from hospital controls in their likelihood of having hypertension, diabetes, or dyslipidaemia, nor, if they had diabetes, in its duration (Table 1).

\section{Microvascular retinopathy}

Microvascular retinopathy was more common in patients with COPD than other hospital patients. One hundred and twenty-one (80\%) COPD patients but only $76(50 \%)$ controls had a microvascular retinopathy (OR 3.98, 95\%CI. 2.39 to 6.64, p < 0.001) (Table 2) (Fig. 1).

In the COPD patients, the microvascular retinopathy was mild in $79(52 \%)$ and moderate in $42(28 \%)$. Both the mild and moderate retinopathy were more common in patients with COPD 


\section{Kidney Blood Pressure Research}

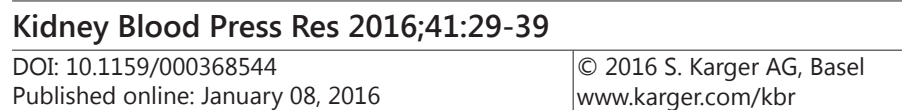

www.karger.com/kbr

Chew et al.: Hypertensive/Microvascular Disease and COPD

Table 1. Clinical features in patients with COPD and hospital controls. BMI - body mass index, eGFR - estimated glomerular filtration rate

\begin{tabular}{lccccc}
\hline & $\begin{array}{c}\text { COPD } \\
(\mathrm{n}=151)\end{array}$ & $\begin{array}{c}\text { Controls } \\
(\mathrm{n}=151)\end{array}$ & $\begin{array}{c}\text { OR/mean } \\
\text { difference }\end{array}$ & 95\% CI & P value \\
\hline Age (years, mean SD) & $69(9.7)$ & $69(7.6)$ & 1.00 & -1.97 to 1.97 & 1.00 \\
Gender (male) & $80(53 \%)$ & $80(53 \%)$ & 1.00 & 0.63 to 1.57 & 1.00 \\
Hypertension & $95(63 \%)$ & $80(53 \%)$ & 1.50 & 0.95 to 2.38 & 0.10 \\
No. antihypertensive medications (mean, SD) & $2.2(1.1)$ & $1.9(0.8)$ & 0.30 & 0.08 to 0.52 & 0.01 \\
Diabetes & $39(26 \%)$ & $36(24 \%)$ & 1.11 & 0.66 to 1.88 & 0.79 \\
Dyslipidaemia & $61(40 \%)$ & $46(31 \%)$ & 1.55 & 0.92 to 2.49 & 0.09 \\
BMI (Kg/m ${ }^{2}$, mean, SD) & $28.0(7.0)$ & $26.6(6.0)$ & 1.40 & -0.08 to 2.88 & 0.06 \\
Smoking history & $143(95 \%)$ & $85(56 \%)$ & 13.88 & 6.35 to 30.32 & $<0.01$ \\
Pack years (median, range) & $40(0-126)$ & $2(0-100)$ & & & $<0.001$ \\
eGFR (ml/min/1.73m ${ }^{2}$, mean, SD) & $69.6(19.4)$ & $83.0(9.1)$ & -13.40 & -16.83 to -9.97 & $<0.001$ \\
\hline
\end{tabular}

Table 2. Retinal abnormalities in patients with COPD and hospital controls. NA - not applicable

\begin{tabular}{lccccc}
\hline Retinal abnormality & COPD $(\mathrm{n}=151)$ & $\begin{array}{c}\text { Controls } \\
(\mathrm{n}=151)\end{array}$ & OR & 95\% CI & P value \\
\hline Haemorrhage & $38(25 \%)$ & $18(12 \%)$ & 2.48 & 1.34 to 4.59 & 0.005 \\
Microvascular retinopathy & $121(80 \%)$ & $76(50 \%)$ & 3.98 & 2.39 to 6.64 & $<0.001$ \\
None & $30(20 \%)$ & $75(50 \%)$ & 0.25 & 0.15 to 0.42 & $<0.001$ \\
Mild & $79(52 \%)$ & $58(38 \%)$ & 1.76 & 1.11 to 2.78 & 0.03 \\
Moderate & $42(28 \%)$ & $18(12 \%)$ & 2.85 & 1.55 to 5.23 & $<0.01$ \\
\hline
\end{tabular}

Fig. 1. Features of microvascular retinopathy in patients with COPD: (a) dot and blot haemorrhages (arrows); (b) arteriovenous nicking (arrow); (c) decreased arteriole (large arrow) and venous (small arrow) ratio; d. focal arteriolar narrow (big arrow); (e) arteriovenous nicking (arrow) with cotton wool spot to the left; and f. tortuous arterioles and venules.

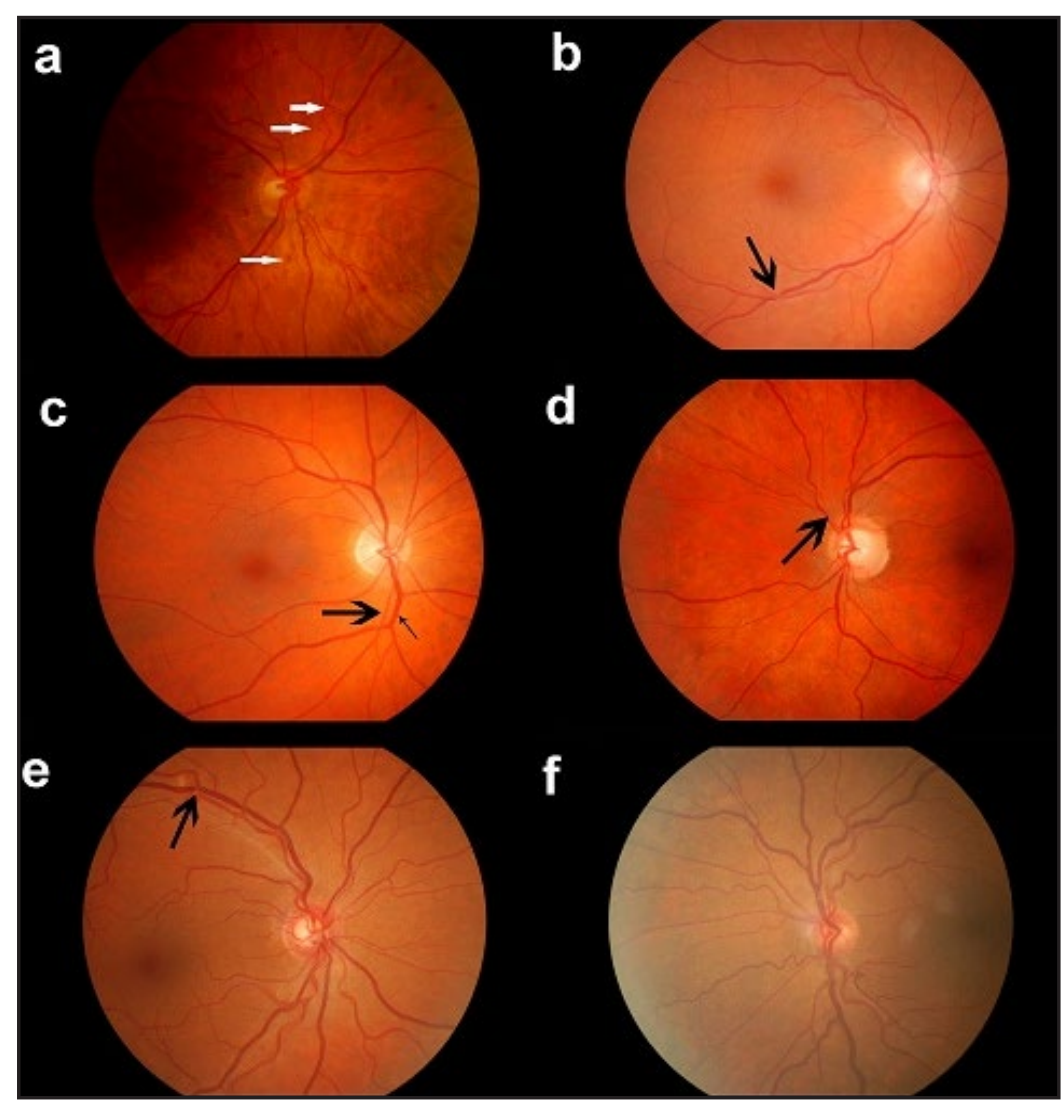




\section{Kidney \\ Blood Pressure Research}

Table 3. Determinants of microvascular retinopathy

\begin{tabular}{|c|c|c|c|c|c|c|c|c|}
\hline \multirow[b]{2}{*}{ Variables } & \multicolumn{2}{|l|}{ Univariate } & \multicolumn{6}{|c|}{ Multivariate analysis } \\
\hline & OR $(95 \% \mathrm{CI})$ & $\begin{array}{c}\mathrm{p}- \\
\text { value }\end{array}$ & $\begin{array}{c}\text { Model 1 - OR } \\
(95 \% \mathrm{CI})\end{array}$ & $\begin{array}{c}\mathrm{p}- \\
\text { value }\end{array}$ & $\begin{array}{c}\text { Model } 2-\text { OR } \\
(95 \% \mathrm{CI})\end{array}$ & $\begin{array}{c}\mathrm{p}- \\
\text { value }\end{array}$ & $\begin{array}{c}\text { Model 3-OR } \\
(95 \% \mathrm{CI})\end{array}$ & $\begin{array}{c}\mathrm{p}- \\
\text { value }\end{array}$ \\
\hline Age (years) & 1.02 (1.00 to 1.05$)$ & 0.08 & & & & & & \\
\hline Male gender & 1.87 (1.16 to 3.02$)$ & 0.01 & 2.15 (1.22 to 3.79$)$ & $<0.01$ & $1.53(0.94$ to 2.60$)$ & 0.09 & $2.01(1.19-3.70)$ & 0.01 \\
\hline Smoking history & $1.92(1.12$ to 3.24$)$ & 0.02 & 0.77 (0.39 to 1.52$)$ & 0.45 & & & $0.59(0.26$ to 1.30$)$ & 0.19 \\
\hline Pack years & & $<0.001$ & & & 1.02 (1.00 to 1.03 ) & 0.001 & $1.00(0.99$ to 1.02$)$ & 0.21 \\
\hline Hypertension & 2.15 (1.33 to 3.49 ) & $<0.01$ & 1.73 (1.02 to 2.93 ) & 0.04 & 1.87 (1.12 to 3.08$)$ & 0.02 & 1.67 (0.98 to 2.83 ) & 0.06 \\
\hline Number of AHM* & $1.29(1.06$ to 1.57$)$ & 0.01 & & & & & & \\
\hline Diabetes & $1.60(0.90$ to 2.86$)$ & 0.11 & & & & & & \\
\hline Diabetes duration & $1.05(1.00$ to 1.11$)$ & 0.04 & 1.05 (1.01 to .11) & 0.03 & $1.05(1.00$ to 1.10$)$ & 0.045 & $1.06(1.00$ to 1.11$)$ & 0.04 \\
\hline Dyslipidaemia & $1.40(0.85$ to 2.32$)$ & 0.19 & & & & & & \\
\hline COPD & $3.98(2.39$ to 6.64$)$ & $<0.01$ & $4.56(2.49$ to 8.36$)$ & $<0.01$ & & & $4.04(2.15$ to 7.58$)$ & $<0.001$ \\
\hline $\begin{array}{l}\text { 1. } \quad \text { Adjusted for } \\
\text { 2. } \\
\text { 3. } \\
\text { *AHM } \\
\text { Adjusted fontihyper for } \\
\end{array}$ & $\begin{array}{l}\text { der, smoking histor } \\
\text { der, pack years, hyp } \\
\text { der, smoking histor } \\
\text { ve medications }\end{array}$ & $\begin{array}{l}\text { hyper } \\
\text { rtensi } \\
\text { pack }\end{array}$ & $\begin{array}{l}\text { sion, diabetes dur } \\
\text { and diabetes dura } \\
\text { s, hypertension, }\end{array}$ & $\begin{array}{l}\text { ion, an } \\
\text { on; } \\
\text { abetes }\end{array}$ & $\begin{array}{l}\text { OPD; } \\
\text { ation and COPD }\end{array}$ & osis. & & \\
\hline
\end{tabular}

than hospital controls (OR 1.76, 95\%CI 1.11 to $2.78, \mathrm{p}=0.03$, and OR $2.85,95 \% \mathrm{CI} 1.55$ to 5.23 , $p=0.001$ respectively). None of the patients in either group had a severe microvascular retinopathy with papilloedema.

Thirty-eight (25\%) patients with COPD had a retinal haemorrhage compared with 18 (12\%) hospital controls (OR 2.46, 95\%CI 1.34 to 4.59, $\mathrm{p}=0.005$ ) (Fig. 1). Most retinal bleeds were small and unlikely to have any visual impact.

On univariate analysis, the major determinants of microvascular retinopathy were male gender $(p=0.01)$, smoking history $(p=0.02)$, hypertension $(p<0.01)$, number of antihypertensive medications ( $\mathrm{p}<0.01)$, diabetes duration $(\mathrm{p}=0.04)$, and diagnosis of COPD $(\mathrm{p}<0.01)$ (Table 2). COPD diagnosis remained a significant risk factor for microvascular retinopathy (OR 4.56, 95\% CI 2.49 to 8.36, $\mathrm{p}<0.01$ ) after adjusting for gender, hypertension, and diabetes duration, smoking history and pack years (Table 3). Where COPD, smoking and pack years were all considered, only COPD was an independent determinant.

\section{Retinal vessel calibre}

Eighty-six patients in this study who had had a chest CT scan and their 86 matched controls were examined for retinal arteriole and venular calibre. They comprised 38 males $(44 \%)$ and 48 females (56\%), with a mean age of $65.9 \pm 7.5$ years (range $42-78$ ). Their median $\mathrm{FEV}_{1} / \mathrm{FVC}$ was $49 \%$ (range 22 to $69 \%$ ), and median $\mathrm{FEV}_{1} 1.04$ litres (range 0.38 to $3.30)$. Four (5\%) had GOLD grade 1, $36(42 \%)$ had grade $2,35(40 \%)$ grade 3 , and $11(13 \%)$ grade 4 disease. Fifteen (17\%) patients required home oxygen support. Sixty-five (76\%) with COPD had a chest CT scan, which indicated emphysema in 39 (60\%).

Forty-seven (55\%) patients were current and 39 (45\%) were former smokers, and their mean cigarette exposure was $44.2 \pm 27.5$ pack years. The former smokers had stopped 6 years previously (median, range one month to 35 years).

Controls comprised $36(42 \%)$ males and $50(58 \%)$ females with a mean age of $66.1 \pm$ 9.9 years (range 46 to 85 ). Fourteen (16\%) were current smokers.

Patients with COPD had more cigarette exposure $(\mathrm{p}<0.001)$ and worse renal function $(\mathrm{p}<0.001)$ than the comparison group, but were not different in terms of prevalence of hypertension, diabetes or dyslipidaemia or of BMI.

Arteriolar calibre. Patients with COPD had larger arterioles than other hospital patients (mean CRAE $153.8 \pm 17.1 \mu \mathrm{m}$ and $147.3 \pm 17.1 \mu \mathrm{m}$, respectively; mean difference $6.5 \mu \mathrm{m}$, $95 \%$ CI 1.4 to $11.6, \mathrm{p}=0.01$ ).

Arteriole calibre was not different in current and former smokers $(154.3 \pm 18.0 \mu \mathrm{m}$ and $153.1 \pm 16.2 \mu \mathrm{m}$, respectively; mean difference $-1.2 \mu \mathrm{m}, 95 \% \mathrm{CI} 6.2$ to $-8.6, \mathrm{p}=0.75$ ). Fourteen 


\section{Kidney \\ Blood Pressure Research}

Table 4. Univariate analysis of factors associated wtih retinal vascular calibre in patients with COPD. 95\%CI: 95\% confidenceinterval, BMI: bodymassindex,eGFR: estimated glomerularfiltration rate, Lowserum Albumin $-<36 \mathrm{~g} / \mathrm{L}$

\begin{tabular}{lcccc}
\hline & \multicolumn{2}{c}{ Central Retinal Artery Equivalent $(\mu \mathrm{m})$} & \multicolumn{2}{c}{ Central Retinal Vein Equivalent $(\mu \mathrm{m})$} \\
\cline { 2 - 5 } & Mean difference $(95 \% \mathrm{CI})$ & $\mathrm{p}$ value & Mean difference $(95 \% \mathrm{CI})$ & $\mathrm{p}$ value \\
\hline Age (per year) & $-0.40(-0.9$ to 0.1$)$ & 0.12 & $-0.6(-0.1$ to -1.17$)$ & 0.02 \\
Gender (male vs. female) & $-1.4(-8.8$ to 6.1$)$ & 0.72 & $-4.6(-13.2$ to 3.9$)$ & 0.29 \\
Hypertension (present vs. absent) & $-9.0(-16.3$ to -1.8$)$ & $<0.01$ & $-5.2(-13.7$ to 3.3$)$ & 0.23 \\
BMI (per Kg $/ \mathrm{m}^{2}$ ) & $-0.7(-1.2$ to -0.1$)$ & $<0.01$ & $-0.3(-0.9$ to 0.4$)$ & 0.42 \\
eGFR (per ml $\left./ \mathrm{min} / 1.73 \mathrm{~m}^{2}\right)$ & $0.2(-0.3$ to 0.4$)$ & 0.09 & $0.01(-0.3$ to 0.3$)$ & 0.92 \\
Diabetes (present vs. absent) & $5.1(-1.3$ to 11.5$)$ & 0.12 & $11.1(0.9$ to 21.4$)$ & 0.03 \\
Cigarette smoking (per 10 pack years) & $0.9(0.6$ to 1.8$)$ & 0.04 & $0.3(0.2$ to 0.5$)$ & $<0.01$ \\
Low serum albumin (present vs. absent) & $8.7(-0.6$ to 18.0$)$ & 0.07 & $23.0(6.0$ to 40.0$)$ & 0.01 \\
\hline
\end{tabular}

Table 5. Differences in retinal vascular calibre between patients with COPD and controls. 95\%CI: 95\% confidence interval

\begin{tabular}{|c|c|c|c|c|}
\hline \multirow[t]{2}{*}{ Multivariate analyses } & \multicolumn{2}{|c|}{ Central Retinal Artery Equivalent $(\mu \mathrm{m})$} & \multicolumn{2}{|c|}{ Central Retinal Vein Equivalent $(\mu \mathrm{m})$} \\
\hline & Mean difference $(95 \% \mathrm{CI})$ & p-value & Mean difference $(95 \% \mathrm{CI})$ & p-value \\
\hline Adjusted for age and gender & $6.5(1.4$ to 11.5$)$ & 0.01 & $17.3(9.4$ to 25.5$)$ & $<0.001$ \\
\hline Adjusted for blood pressure, BMI, eGFR & $8.6(3.2$ to 14.0$)$ & $<0.01$ & & \\
\hline Adjusted for blood pressure, BMI, and pack years & $7.1(-0.43$ to 14.7$)$ & 0.06 & & \\
\hline Adjusted for blood pressure, BMI, pack years and eGFR & $8.9(0.7$ to 17.1$)$ & 0.03 & & \\
\hline Adjusted for age and diabetes & & & 16.8 (9.0 to 24.7$)$ & $<0.01$ \\
\hline Adjusted for age, diabetes and pack years & & & $4.6(-7.6$ to 16.8$)$ & 0.46 \\
\hline
\end{tabular}

patients had a low serum albumin $<36 \mathrm{~g} / \mathrm{L}$. Arterioles from patients with a low serum albumin demonstrated a trend to increased calibre compared with those with a normal serum albumin $(158.4 \pm 10.95 \mu \mathrm{m}$ and $149.7 \pm 15.8 \mu \mathrm{m}, \mathrm{p}=0.07)$. Arterioles were wider in COPD patients with a lower blood pressure (mean difference $-9.0 \mu \mathrm{m}, 95 \% \mathrm{CI}-16.3$ to $-1.8, \mathrm{p}<0.01$ ), lower BMI (mean difference $-0.7 \mu \mathrm{m}, 95 \% \mathrm{CI}-1.2$ to $-0.1, \mathrm{p}<0.01)$, and increased pack years $(0.9 \mu \mathrm{m}, 0.6$ to 1.8 , $\mathrm{p}=0.04)$, and there was a trend with eGFR $(0.2,95 \% \mathrm{CI}-0.3$ to $0.4, \mathrm{p}=0.09)$ (Table 4$)$.

Retinal arteriole calibre was then compared in patients with COPD and controls using multivariate linear analysis in different models after adjusting for determinants identified in the univariate analysis (Table 5). The difference in calibre persisted after adjusting for blood pressure, BMI and eGFR ( $\mathrm{p}<0.01)$, and for blood pressure, BMI, eGFR and pack years $(\mathrm{p}=$ $0.03)$ but not for blood pressure, BMI and pack years $(\mathrm{p}=0.06)$.

Venular calibre. Patients with COPD had larger venules than controls (mean CRVE $229.4 \pm 28.0 \mu \mathrm{m}$ and $211.9 \pm 25.5 \mu \mathrm{m}$ respectively; mean difference $17.4 \mu \mathrm{m}, 95 \% \mathrm{CI} 9.4$ to $25.5, \mathrm{p}<0.001$ ).

Venular calibre was not different in current and former smokers $(230.2 \pm 29.8 \mu \mathrm{m}$ and $228.4 \pm 26.1 \mu \mathrm{m}$, respectively; mean difference $-1.8 \mu \mathrm{m}, 95 \% \mathrm{CI}-13.9$ to $10.4, \mathrm{p}=0.77$ ).

Venules were larger in patients with COPD and a low serum albumin $(240.9 \pm 27.5 \mu \mathrm{m})$ than in those with normal levels $(217.9 \pm 17.6 \mu \mathrm{m}, \mathrm{p}=0.01)$. Venules were also larger in COPD patients who were younger $(\mathrm{p}=0.02)$, had diabetes $(\mathrm{p}=0.03)$ and increased pack years $(\mathrm{p}<0.01)$ (Table 4$)$.

Retinal venular calibre was then compared in patients with COPD and controls using multivariate linear regression analysis in different models after adjusting for determinants identified in the univariate analysis (Table 5). The difference in calibre persisted after adjusting for age and diabetes $(\mathrm{p}<0.01)$, but not with age, diabetes and pack years $(\mathrm{p}=0.46)$.

Retinal vessel calibre and COPD severity. Retinal arteriolar calibre was not associated with more severe airways disease as demonstrated by $\mathrm{FEV}_{1}(\mathrm{p}=0.13)$ or $\mathrm{FEV}_{1} / \mathrm{FVC}$ ratio $(\mathrm{p}$ 


\section{Kidney \\ Blood Pressure Research}

Kidney Blood Press Res 2016;41:29-39

\begin{tabular}{l|l}
\hline DOI: $10.1159 / 000368544$ & (c) 2016 S. Karger AG, Basel
\end{tabular}

Published online: January 08, 2016

www.karger.com $/ \mathrm{kbr}$

Chew et al.: Hypertensive/Microvascular Disease and COPD

$=0.83$ ) nor with emphysema on chest CT scan. Arteriolar calibre was also not different in patients with or without emphysema $(155.8 \pm 16.3 \mu \mathrm{m}$ and $152.1 \pm 17.8 \mu \mathrm{m}$ respectively, $\mathrm{p}$ $=0.33$ ).

There were trends for larger retinal venules in patients with more severe airways disease demonstrated by a lower $\mathrm{FEV}_{1}$, (mean difference in CRVE per $10 \mathrm{ml}$ change $\mathrm{FEV}_{1}$ $-11.3 \mu \mathrm{m}, 95 \% \mathrm{CI}-24.6$ to $2.1, \mathrm{p}=0.10$ ) or lower $\mathrm{FEV}_{1} / \mathrm{FVC}$ ratio (mean difference in CRVE per $1 \%$ change $\mathrm{FEV}_{1} / \mathrm{FVC}$ ratio $-0.4 \mu \mathrm{m}, 95 \% \mathrm{CI},-0.8$ to $0.1 \mathrm{p}=0.09$ ). There was also a trend for larger retinal venules in patients with emphysema compared with those without (235.6 $\pm 25.0 \mu \mathrm{m}$ and $224.2 \pm 29.5 \mu \mathrm{m}$, respectively, mean difference $+11.4 \mu \mathrm{m}, 95 \% \mathrm{CI}-0.4$ to 23.4 , $\mathrm{p}=0.06)$.

\section{Discussion}

This study demonstrated that microvascular retinopathy was more common and more severe in patients with COPD than in other age- and gender- matched hospital patients. COPD remained an independent determinant of microvascular retinopathy $(\mathrm{p}<0.01)$ after adjusting for hypertension, smoking, gender and diabetes. In addition, retinal arterioles and venules were wider in patients with COPD. Calibre was greater with increased cigarette exposure, but did not depend on current smoking status. Venular calibre was also increased in patients with a low serum albumin, and there were trends for an association with more severe COPD and CT-demonstrated emphysema.

The study compared retinal abnormalities in patients with COPD and those with normal respiratory function. Clinic patients with normal respiratory function tests were used as controls because they were well-characterised medically.

Patients with COPD had hypertension, dyslipidemia and diabetes, as often as other hospital patients, and diabetes was of similar duration. Patients with COPD required more antihypertensive agents and had worse renal function, which may be explained by their increased vascular disease. Blood pressure severity was assessed by the number of antihypertensive medications needed for treatment. Blood pressure control is difficult to assess, with clinic BP measurements overestimating levels, and ambulatory BP measurements underestimating control.

Diabetes duration rather than diabetic control was used as a risk factor because complications are more likely with longer disease duration and control varies over time. COPD patients were more likely to have been smokers, and to have smoked more than other patients. However some of the COPD patients had never smoked, while half those with normal respiratory function had smoked, generally for shorter periods of time.

Both mild and moderate microvascular retinopathy were increased in patients with COPD, and COPD was the strongest determinant of microvascular retinopathy even after adjusting for hypertension diagnosis, smoking history, gender and diabetes duration. COPD and hypertension share risk factors, the most important of which are probably age and smoking. These were examined in the univariate analysis and also taken into account in the multivariate analysis, but the results demonstrated that the effects of COPD persisted. The observation that COPD was a risk factor for small vessel disease independent of smoking and hypertension suggested hypertension measurement was important or there was a role for another COPD-related mechanism, such as inflammation [24]. The finding of microvascular retinopathy itself has implications for COPD patients since population-based studies have demonstrated it predicts cardiac events [25, 26], chronic heart failure [27] and stroke, in high-risk individuals [28].

Both retinal arteriole and venular calibre were increased in patients with COPD. Microvascular dilatation has been found previously in smokers [13] but was demonstrated here in former smokers too. Smoking has complex and sometimes long-lasting effects on the small vessels. It contributes to arteriolar narrowing through atherosclerosis, hypertension 


\section{Kidney \\ Blood Pressure Research}

and renovascular disease, and to venular dilatation by toxin-induced endothelial damage, reduced vasoactive mediators, tissue hypoxaemia and autonomic dysregulation.

There were trends for an association between wider venules and more severe COPD, consistent with a shared determinant, such as smoking, or a causal relationship, for example, hypoxaemia or chronic low grade infection. This study also suggested a trend between venular dilatation and emphysema. Previously, pulmonary microvascular dilatation in emphysema was thought to reflect the destruction of local supporting tissue and subsequent remodelling [29], but it is likely that early vascular widening occurs, at least in part, because of inflammation and not primarily from pulmonary damage.

Larger venules were associated with low serum albumin levels in COPD too. The albumin levels possibly reflected inflammation from smoking-induced damage, low grade respiratory tract infections or COPD exacerbations. A low serum albumin correlates better with inflammation than the elevated white cell counts that also occur with stress and corticosteroid use, but which are absent in the frail unwell. $\mathrm{C}$ reactive protein levels may be normal or low in inflammation where there is impaired hepatic synthetic function. Low serum albumin was unlikely to reflect malnutrition since the patients' average BMI was above the recommended normal range and few had severe end-stage COPD.

The major strengths of this study were that participants were well-characterised, the recruitment rate was high, COPD was diagnosed with spirometry, and widely- accepted, reproducible grading systems were used to assess microvascular retinopathy and calibre. Hospital patients were used as the comparison group because their comorbidities were well-documented and, although they were more likely to be smokers and any difference in vessel calibre therefore less pronounced, the cohort was still large enough to demonstrate a difference with COPD patients. The major limitations of this study were that it was performed at a single centre, and that the causes of microvascular retinopathy and calibre changes are complex. In the first instance these results need to be confirmed in an independent study. However these results still indicate that patients with COPD have an increased risk of microvascular disease compared with other hospital patients and hence that hospital resources might focus on this disease group.

\section{Conclusion}

Patients with COPD have a greater risk of microvascular disease and more severe disease than other hospital patients [30]. Retinal vessels are larger in patients with COPD. Cigarette exposure and chronic inflammation may contribute to microvascular disease, and the systemic microvasculature, including the coronary small vessels, will be affected too. In other, population-based studies, retinal venular dilatation predicts cardiac events [12].

\section{Disclosure Statement}

The authors report no conflicts of interest. There was no commercial funding for this study. Part of this work was presented in Abstract form at the American Thoracic Society Conference, Denver 2011.

\section{Acknowledgements}

The authors are grateful to all the patients who participated in this study and to Sherine Yousef who performed the respiratory function tests.

This study was performed by Sky Chew, Alex Wong and Vi Luong when they were medical students as part of the B Medical Science research programme at the University of Melbourne. 


\section{Kidney \\ Blood Pressure Research}

SC recruited the patients and took their retinal photographs; DC and SC graded the retinal images; PC referred the patients for the study; AH performed the statistical analysis; AW and VI helped with the statistical analysis; TY was responsible for the retinal vessel grading; and JS was responsible for the study overall, and for the drafting of the manuscripts and the data integrity.

\section{References}

1 Halbert R, Natoli J, Gano A, Badamgarav E, Buist A, Mannino D: Global burden of COPD: Systematic review and meta-analysis. Eur Respir J 2006;28:523-532.

2 Barnes PJ, Celli BR: Systemic manifestations and comorbidities of COPD. Eur Respir J 2009;33:1165-1185.

3 Terzano C, Conti V, Di Stefano F, Petroianni A, Ceccarelli D, Graziani E, Mariotta S, Ricci A, Vitarelli A, Puglisi G, De Vito C, Villari P, Allegra L: Comorbidity, hospitalization, and mortality in COPD: Results from a longitudinal study. Lung 2010;188:321-329.

4 Pradhan AD, Manson JE, Rifai N, Buring JE, Ridker PM: C-reactive protein, interleukin 6, and risk of developing type 2 diabetes mellitus. JAMA 2001;286:327-334.

5 Rana JS, Mittleman MA, Sheikh J, Hu FB, Manson JE, Colditz GA, Speizer FE, Barr RG, Camargo CA, Jr:: Chronic obstructive pulmonary disease, asthma, and risk of type 2 diabetes in women. Diabetes Care 2004;27:2478-2484.

6 Chen W, Thomas J, Sadatsafavi M, FitzGerald JM: Risk of cardiovascular comorbidity in patients with chronic obstructive pulmonary disease: A systematic review and meta-analysis. Lancet Respir Med 2015;3:631-639.

7 Peinado VI, Barbera JA, Ramirez J, Gomez FP, Roca J, Jover L, Gimferrer JM, Rodriguez-Roisin R: Endothelial dysfunction in pulmonary arteries of patients with mild COPD. Am J Physiol 1998;274:L908-913.

8 Maclay JD, McAllister DA, MacNee W: Cardiovascular risk in chronic obstructive pulmonary disease. Respirology 2007;12:634.

9 Westlin WF, Gimbrone MA Jr: Neutrophil-mediated damage to human vascular endothelium. Role of cytokine activation. Am J Pathol 1993;142:117.

10 Harris B, Klein R, Jerosch-Herold M, Hoffman EA, Ahmed FS, Jacobs DR, Jr., Klein BE, Wong TY, Lima JA, Cotch MF, Barr RG: The association of systemic microvascular changes with lung function and lung density: A cross-sectional study. PLoS One 2012;7:e50224.

11 Wong TY, Islam FM, Klein R, Klein BE, Cotch MF, Castro C, Sharrett AR, Shahar E: Retinal vascular caliber, cardiovascular risk factors, and inflammation: The Multi-Ethnic Study of Atherosclerosis (MESA). Invest Ophthalmol Vis Sci 2006;47:2341-2350.

12 Wong TY, Kamineni A, Klein R, Sharrett AR, Klein BE, Siscovick DS, Cushman M, Duncan BB: Quantitative retinal venular caliber and risk of cardiovascular disease in older persons: The Cardiovascular Health Study. Arch Intern Med 2006;166:2388-2394.

13 Hughes AD, Wong TY, Witt N, Evans R, Thom SA, Klein BE, Chaturvedi N, Klein R: Determinants of retinal microvascular architecture in normal subjects. Microcirculation 2009;16:159-166.

14 Kifley A, Liew G, Wang JJ, Kaushik S, Smith W, Wong TY, Mitchell P: Long-term effects of smoking on retinal microvascular caliber. Am J Epidemiol 2007;166:1288-1297.

15 Klein R, Klein BE, Knudtson MD, Wong TY, Tsai MY: Are inflammatory factors related to retinal vessel caliber? The Beaver Dam Eye Study. Arch Ophthalmol 2006;124:87-94.

16 Wong TY, Duncan BB, Golden SH, Klein R, Couper DJ, Klein BE, Hubbard LD, Sharrett AR, Schmidt MI: Associations between the metabolic syndrome and retinal microvascular signs: The Atherosclerosis Risk in Communities study. Invest Ophthalmol Vis Sci 2004;45:2949-2954.

17 Klein R, Klein BE, Moss SE, Wong TY, Sharrett AR: Retinal vascular caliber in persons with type 2 diabetes: The Wisconsin epidemiological study of diabetic retinopathy. Ophthalmology 2006;113:1488-1498.

18 Ferris BG: Epidemiology standardization project (American Thoracic Society). Am Rev Respir Dis 1978;118:1-120. 


\section{Kidney \\ Blood Pressure Research}

Kidney Blood Press Res 2016;41:29-39

DOI: 10.1159/000368544

Published online: January 08, 2016

(c) 2016 S. Karger AG, Basel

www.karger.com/kbr

19 ATS statement--Snowbird workshop on standardization of spirometry. Am Rev Respir Dis 1979;119:831838.

20 Buist AS, McBurnie MA, Vollmer WM, Gillespie S, Burney P, Mannino DM, Menezes AM, Sullivan SD, Lee TA, Weiss KB, Jensen RL, Marks GB, Gulsvik A, Nizankowska-Mogilnicka E: International variation in the prevalence of COPD (the BOLD study): A population-based prevalence study. Lancet 2007;370:741-750.

21 Wong TY, Mitchell P: Hypertensive retinopathy. N Engl J Med 2004;351:2310-2317.

22 Wong TY, Knudtson MD, Klein R, Klein BE, Meuer SM, Hubbard LD: Computer-assisted measurement of retinal vessel diameters in the Beaver Dam Eye Study: Methodology, correlation between eyes, and effect of refractive errors. Ophthalmology 2004;111:1183-1190.

23 Hubbard LD, Brothers RJ, King WN, Clegg LX, Klein R, Cooper LS, Sharrett AR, Davis MD, Cai J: Methods for evaluation of retinal microvascular abnormalities associated with hypertension/sclerosis in the Atherosclerosis Risk in Communities study. Ophthalmology 1999;106:2269-2280.

24 Stone IS, Barnes NC, Petersen SE: Chronic obstructive pulmonary disease: A modifiable risk factor for cardiovascular disease? Heart 2012;98:1055-1062.

25 Duncan BB, Wong TY, Tyroler HA, Davis CE, Fuchs FD: Hypertensive retinopathy and incident coronary heart disease in high risk men. Br J Ophthalmol 2002;86:1002-1006.

26 Wong TY, Klein R, Sharrett AR, Duncan BB, Couper DJ, Tielsch JM, Klein BE, Hubbard LD: Retinal arteriolar narrowing and risk of coronary heart disease in men and women. The Atherosclerosis Risk in Communities study. JAMA 2002;287:1153-1159.

27 Wong TY, Rosamond W, Chang PP, Couper DJ, Sharrett AR, Hubbard LD, Folsom AR, Klein R: Retinopathy and risk of congestive heart failure. JAMA 2005;293:63-69.

28 Wong TY, Klein R, Couper DJ, Cooper LS, Shahar E, Hubbard LD, Wofford MR, Sharrett AR: Retinal microvascular abnormalities and incident stroke: The Atherosclerosis Risk in Communities study. Lancet 2001;358:1134-1140.

29 Wiebe BM, Laursen H: Lung morphometry by unbiased methods in emphysema: Bronchial and blood vessel volume, alveolar surface area and capillary length. APMIS 1998;106:651-656.

30 Joussen AM, Poulaki V, Le ML, Koizumi K, Esser C, Janicki H, Schraermeyer U, Kociok N, Fauser S, Kirchhof B, Kern TS, Adamis AP: A central role for inflammation in the pathogenesis of diabetic retinopathy. FASEB J 2004;18:1450-1452. 